\title{
Gender Differences in Stressors and Coping Strategies Among Teacher Education Students at University of Ghana
}

\author{
Grace S. Adasi ${ }^{1}$, Kwaku D. Amponsah ${ }^{2}$, Salifu M. Mohammed ${ }^{2}$, Rita Yeboah ${ }^{2} \&$ Priscilla C. Mintah ${ }^{3}$ \\ ${ }^{1}$ Institute of African Studies, University of Ghana, Legon, Accra, Ghana \\ ${ }^{2}$ Department of Teacher Education, University of Ghana, Legon, Accra, Ghana \\ ${ }^{3}$ Department of Educational Psychology, Faculty of Educational Studies, University of Cape Coast, Cape Coast, \\ Ghana
}

Correspondence: Kwaku D. Amponsah, Department of Teacher Education, P. O. Box LG 1181, University of Ghana, Legon, Accra, Ghana. E-mail: kdamponsah@ug.edu.gh

$\begin{array}{ll}\text { Received: December 29, } 2019 & \text { Accepted: January 30, } 2020 \quad \text { Online Published: February 24, } 2020 \\ \text { doi:10.5539/jel.v9n2p123 } & \text { URL: https://doi.org/10.5539/jel.v9n2p123 }\end{array}$

\begin{abstract}
This study explored gender differences in stressors experienced by teacher education students at the University of Ghana, and adaptation stratagems they might utilise to manage stress. In 2018-2019 academic year, a total of two hundred and seventy (270) second- and third-year students were selected using random sampling procedure to respond to closed-ended and open-ended questions in a survey questionnaire. The questionnaire was adapted from Dental Environmental Stress (DES) to measure stressors students encounter and the Brief Coping Orientation to Problems Experienced (Brief COPE) to measure students' coping stratagems they might use to minimise their stress levels (Folkman \& Lazarus, 1984). It was pre-tested to learners of the faculty of education at the University of Cape Coast, Ghana, to ensure the reliability and validity of the statements. The findings show that the students use multiple strategies, such as praying/meditating and self-distracting activities to cope with stress. Although, females had higher overall perceived stress levels regarding encountered academic stressors and health stressors, the difference between genders was insignificant. Similarly, females had a higher perception of stress from psychosocial stressors when likened to males, however, the difference between genders was also insignificant. Regarding perceived coping stratagems, females utilised adaptive coping stratagems whilst males utilised maladaptive and avoidance coping stratagems although the difference between genders was also not significant. The study recommended among others that males be urged to likewise utilise increasingly adaptive strategies to control strain.
\end{abstract}

Keywords: gender, stressors, teacher education students, coping strategies

\section{Introduction}

Stress might be a productive or a terrible condition of psychological and functional stimulation that an individual might encounter in circumstances that they see as perilous or intimidating to their psychosocial wellness. Stress has various implications for countless individuals as it is not culture specific or bound to affect some group of people, but rather comes to everyone regardless of age, educational background, geographical location or status in life. Stress is a significant issue among university students as they endeavour to take control of scholastic, social and personal encounters (Amponsah \& Owolabi, 2011). All things considered, the vast majority of students have encountered strain or tension in the course of their education at one point or the other, particularly college students, as a result of the numerous burdens encountered in academia. Various investigations have been directed to look at the uneasiness of college learners and the issues that impact their feelings of anxiety. A wide range of elements related to stress among university students has progressively been looked into in the most recent times. Especially, extreme stress might negatively impact scholarly execution and wellbeing and can prompt mental misery with side effects of nervousness and wretchedness. Students might encounter feelings of diminished individual accomplishment and lack of engagement and apathy with their studies, further adversely affecting scholastic learning as a result of sustained mental misery that could cause scholarly burnout, a condition of passionate weariness (Lin \& Huang, 2014; Tomaschewski-Barlem, Lunardi, Ramos, Da Silveira, Devos-Barlem, \& Ernandes, 2014). 
Likewise, learners experience a great deal of pressure while they are at school. These stressors originate from a mix of numerous variables including strain to perform scholastically, demanding classes, difficult tests, combined with the autonomous nature of the learning arrangement at the university level. Once more, many learners experience monetary pressure that includes the battle to obtain adequate cash to pay for educational cost, as well as finding the funds expected to take care of one's living expenses. Learners feel strain to settle on instructive and vocational choices that can affect the rest of their lives. Most students face social pressure, living with a flatmate, harmonising companionship with school work and managing the elements of youthful-elderly relations that can be troublesome. A few learners shield insane hours from keeping awake until late to learn, rising ahead of schedule for lectures, and attempting to squeeze in all the work and fun at the same time. Similarly, most learners battle with what their identity is and where they would prefer to be, in any event, sooner or later in their student vocation (Lin \& Huang, 2014; Tomaschewski-Barlem et al., 2014).

Coping or adapting skills largely determine how individuals experience anxiety. Generally, adapting alludes to conduct that shields individuals from being mentally hurt by a tricky social encounter. Some of the strategies that learners might utilise to deal with stress include making contacts, avoidance, designation, powerful correspondence, discovering fulfillment, exercise, prioritising the amount of work to be done, in the hunt for relief in eating food, smoking and counselling as a form of outside exhortation (Amponsah \& Owolabi, 2011; Tomaschewski-Barlem et al., 2014 ). Finding solutions to some of these challenges may be frustrating, conflicting and pressurising. It would, therefore, be essential to examine the stressors they encounter and the coping stratagems they might employ.

\subsection{Statement of the Problem}

The department of Teacher Education is one of three departments located in the School of Education and Leadership, College of Education at the University of Ghana, Legon, Accra, Ghana. The department is the first ever established in this University to train teachers for both Junior high schools (JHSs) and Senior high schools (SHSs) in Ghana. Student teachers trained for the JHSs offer all their courses in the department but those trained for SHSs offer education-related courses in the department and borrow teaching courses like science, mathematics, and English, from other departments. Additionally, student teachers in the JHS programme do not borrow courses from other departments. Consequently, student teachers pursuing secondary education took part in this study since at the time of the study there were no students admitted into the JHS programme. Thus, the uniqueness of this department in terms of courses, and students having to borrow their teaching courses from two or three departments and the fact that it comes with an exclusive vision prompted this study.

Literature has revealed that there are gender differences in some types of pressure encountered by the majority of learners in their pursuit of higher education. Similarly, there are gender differences among Ghanaian university students when faced with rigorous academic demands such as meeting deadlines for assignments and presentations and planning for tests and examinations. Additionally, differences exist between males and females in fulfilling time constraints for turning in of assignments combined with school work and additional societal obligations (Amponsah \& Owolabi, 2011; Gyambrah, Sesay, \& Amponsah, 2017; Kumi-Yeboah, 2010; Kwaah \& Essilfie, 2017; Torto, 2009). These scholarly exercises combined with other psychosocial duties among teacher education students by gender have received little research consideration to inform policy and practice in the Ghanaian situation. It is worth noting that the studies mentioned earlier were conducted in universities in Ghana whose traditional mandate is to produce teachers for the first and second cycle of institutions in Ghana. Students in those Ghanaian universities are accustomed to issues related to teacher education unlike the students used in these studies. Apart from Amponsah and Owulabi (2011) who used Freshers in a traditional education university in Ghana, the rest used distance education students from two traditional education universities also in Ghana. The psychosocial circumstances of distance education students are relatively different from regular education students. Additionally, the teacher education programme is quite new at the university where the research was conducted. Not withstanding, every new programme is bedevilled with its own teething and attendant challenges and the teacher education programme is no exception. It is therefore expedient to explore gender differences in stressors encountered by the learners of teacher education and the coping strategies that they might adopt to overcome stress.

Consequently, the effects of these stressful circumstances on students by gender and the coping strategies adopted to reduce or eliminate them are of great concern and a call for investigation, which will go a long way to enhance the knowledge about the effectiveness of the strategies. Should these stressful conditions continue to exist with no appropriate strategy to curb or control them, the students would go through difficult times to cope with them physiologically or mentally and might affect their academic achievement. It is against this backdrop that this study was conducted to explore gender differences among teacher education learners of the University 
of Ghana in stressors that they might encounter and coping strategies they might also utilise to manage stress.

\subsection{Purpose of the Study}

This research investigated gender differences in stressors among teacher education students of the University of Ghana and the adaptation stratagems they might utilise to manage stress. Understanding the factors that contribute to students' stress is necessary for appreciating the efficiency of coping strategies in improving stress management programmes. It is hoped that by exploring stressors and coping mechanisms utilised by teacher education students, the tension can be reduced, enabling them to perform effectively and efficiently in their scholastic undertaking.

\subsection{Research Questions}

1) What are the stressors encountered by male and female teacher education students?

2) What coping strategies do male and female teacher education students employ to control stress?

3) How do male students differ from female students regarding stressors they encounter?

4) How do male students differ from female students regarding the kind of coping stratagems they employ to control stress?

\section{Review of Related Literature}

\subsection{Theoretical Framework}

Cognitive appraisal or psychological evaluation (commonly addressed as 'appraisal') is the emotional elucidation made by a person to an event that evokes a specific functional reaction in the surrounding. Psychological evaluation is a constituent in an assortment of suppositions that identify with strain, psychological well-being, adapting, and sentimentality.

Lazarus' transactional model of stress utilises psychological evaluation as an approach to disclose reactions to distressing circumstances (Lazarus, 1984; Lazarus \& Folkman, 1984). Within this model, a psychological evaluation is characterised as the manner a person reacts to and deciphers the causes of stress throughout everyday life. An assortment of psychological syndromes has been seen as having anomalous styles of psychological evaluation in the individuals who are influenced by the turmoil. The theory discusses two particular kinds of psychological evaluation namely, "primary appraisal" and "secondary appraisal" that need to happen for a person to be stressed in reaction to an occurrence (Lazarus, 1984). Throughout primary appraisal, a condition is deciphered as hazardous to the person or dangerous to their objectives. Similarly, all through secondary appraisal, the person determines that they have an inadequate strategy that may be adopted to overcome the adverse circumstance. At the point when the inadequate condition happens, the occasion causes a strain as a reaction (Lazarus, 1984).

Scherer's component process model utilises psychological evaluation to clarify a person's mental and physiological reaction to circumstances. Lazarus' transactional model is augmented by this model concerning what number of evaluations happen. Scherer's model recommends that four particular evaluations happen as opposed to only two degrees of evaluation in reaction to an occasion (primary and secondary) as proposed by Lazarus. Scherer's four categorical appraisals include: (a) the direct impacts or importance that a person perceives a circumstance is to them (b) the short-term and long-term outcomes a circumstance has concerning persons and their objectives (c) the capacity a person notices they can adapt to the outcomes of a circumstance (d) how the circumstances are seen to result based on a person's standards and self-concept (Scherer, 2009). Further research by Scherer draws special attention to mental reactions, as well as numerous physiological reactions as indicated by how situations are assessed by an individual (Scherer, 2009).

Finally, in contrast with Lazarus' transactional model, Roseman's appraisal theory of emotions utilised the idea of psychological evaluation (cognitive appraisal) to assemble an illustrative theory that incorporates a more extensive scope of feelings. Accordingly, Roseman (1996) indicated that positive feelings arise from occasions that a person evaluates as reliable concerning their thought processes, while negative feelings also arise from circumstances that people assess as conflicting with their intentions. More explicit feelings depend on the perception of the occasion being brought about by others, the individual, or because of an irrepressible situation (Roseman, 1996).

The theoretical frameworks discussed thus far are reinforced by cognitive appraisal which is the emotional elucidation made by a person to an event that evokes a specific functional reaction in the surrounding. Consequently, the stressors experienced by learners and the coping strategies they adopt to offset the stress are underpinned by cognitive appraisal, which is the pivot of the four theories discussed. The event mentioned in 
cognitive appraisal is the stressful situation encountered by an individual, and emotional elucidation is the coping stratagems adopted to manage stress.

\subsection{Empirical Review}

How stress is psychologically evaluated has been found to impact emotional well-being of individuals (Gomes, Faria, \& Lopes, 2016). Cognitive styles of seeing the world and deciphering circumstances have been proposed as variables that may make certain people progressively inclined to despondency. An assortment of studies has connected fright syndrome with attentional predispositions and a calamitous view of situations (Craighead, 2008).

Studies within the past two decades have revealed an occurrence of stress among learners at the university level (Robotham \& Julian, 2006). Other researches have been conducted to interrogate issues related to differences between males and females regarding the perception of stress. For instance, a study was conducted to "examine the relationships between stress level and academic achievement among students in urban and rural secondary schools in one of the districts in Malaysia. The findings of the study indicated that there are significant differences in the level of stress for gender" (Tajularipin, Aminuddin, Vizata, \& Saifuddin, 2009, p. 43). Similarly, an investigation was conducted to "assess the levels of stress encountered by university students at Tafila Technical University. The results revealed that female students encountered more stress than male students, however, male students were influenced more by monetary issues than females" (Thawabieh \& Qaisy, 2012, p. 110).

Again, a study was undertaken to "investigate gender influence on perceived stress level and coping strategies of undergraduate university students in Kenya" (Misigo, 2015, p. 44). Findings from the investigation revealed that a "significant difference existed between the stress mean scores of males and females. Female students reported higher stress levels than males. Female participants also reported positive stress coping skills such as seeking help from counsellors and friends, whereas male participants reported negative coping strategies such as taking alcohol and drug use" (Misigo, 2015, p. 44).

Additionally, an investigation was undertaken to examine the "sources of stress (academics, financial, family, social, and daily hassles) and the coping strategies (self-help, approach, accommodation, avoidance, and self-punishment) of 166 college students. The relationship between sex, specific sources of stress, and coping strategies was also investigated. The results revealed that college women reported a higher overall level of stress and greater use of emotion-focused coping strategies than college men. Again, college men and women also reported different coping strategies for different stressors; however, the use of emotion-focused coping strategies dominated problem-solving strategies for both men and women" (Brougham, Zail, Mendoza, \& Miller, 2009, p. $85)$.

Similarly, research was conducted to "examine the relationship between gender and reactions to stress among university students, specifically on how they typically responded when under perceived stress. The findings showed that there were significant differences between males and females concerning their reactions to stress. Overall, more females experienced higher levels of depression, frustration, and anxiety than their male counterparts when reacting to stress. Males also tended to have other psychological reactions different from those listed on the survey. Also, while the stress reaction of anger was barely statistically insignificant, more females expressed anger than males as a reaction to stress" (Calvarese, 2015, p. 1177).

Besides, another study was undertaken to "explore gender differences in the perceived level of stress and coping strategies among college students in India. The results indicated that female undergraduate students had high levels of stress than male undergraduate students. Other findings of the study also indicated that male participants had higher stress coping scores than female participants. The study revealed that male students are more likely to use better stress coping strategy than female students" (Anbumalar, Dorathy Agines, Jaswanti, Priya, \& Reniangelin, 2017, p. 2349).

Furthermore, another research investigated "the relationship between gender differences and stress. It was hypothesised that females would express more stress than males, that females would experience more stress on the math task than the spelling task, and that males would not experience a large difference in stress levels on the math and spelling tasks. Consequently, a math task and a spelling task were used to create stress and a 10-point stress scale was used to measure the stress levels of the participants. The results were insignificant and did not support the hypothesis, revealing almost no difference between stress levels of males and females on both tasks" (Kania, 2014, p. 91).

Contrarily, other researches have revealed that male learners encounter elevated degrees of pressure compared 
with female learners. Findings from an investigation suggested that male learners experience elevated degrees of pressure, serious mental wellness, and encountering fewer tendencies towards utilising constructive adapting procedures (Chen, Wong, Ran, \& Gilson, 2009). Correspondingly, Sitz and Poche (2006) also revealed that females demonstrated more hopefulness than males and possess lesser degrees of perceived strain in comparison with males. These previous researches have shown that there are conflicting results concerning the degree of stress exhibited by males and females, thereby activating additional research of this circumstance.

In connection with coping stratagems, differences have also been found to exist between males and females. It was revealed that females utilise social support and assistance seeking behaviour as a coping approach. However, it was discovered that males react to unpleasant circumstances by picking either dynamic adapting methodologies or avoidant procedures, for example, liquor or medication use (Aldwin, 2007; Dyson \& Renk, 2006). Also, females frequently select emotionally focused coping tactics such as looking for help or positive reframing (Desmarias \& Alksnis, 2005; Dyson \& Renk, 2006). Nevertheless, some researches have shown no gender differences regarding coping approaches males and females utilised to control stressful situations (Donaldson, Prinstein, Danorsky, \& Spirits, 2000). Similarly, Thoits (1995) reported that although gender is perceived to influence the relationship between anxiety and the category of coping stratagems selected, the findings might sometimes be unreliable.

\section{Method}

\subsection{Research Design}

The study utilised a cross-sectional descriptive survey design to investigate the differences between male and female learners regarding stressors and coping approaches they might adopt to minimise stress. The purpose of using the survey design was to interrogate teacher education students concerning stressors they encounter and the adaptation strategies they might employ to offset or minimise the stress. This type of research design is mainly concerned with the description of some phenomena. The economic benefits of a cross-sectional descriptive survey design justified its choice in this study as results are obtained more rapidly. Similarly, sampling has greater coverage with regards to the assortment of information needed and additionally, it takes into account greater quality of work as increasingly precise information can be given under appropriate circumstances. Sample surveys have some weaknesses with regards to getting fundamental information needed for every unit of the populace. Mistakes regarding sampling also tend to be greater for small sample sizes. Nevertheless, given the consistency and extent of the target population of this research, the benefits in the descriptive sample survey far outweigh its weaknesses.

\subsection{Population and Sample}

The population of the study consists of teacher education students offering undergraduate education programmes at the University of Ghana during the 2018/2019 academic year. Two hundred and seventy second and third year teacher education students comprising 144 females and 126 males pursuing programmes in English Education, General Education, Mathematics Education and Science Education took part in this investigation. The ages of respondents ranged between 17 and 26 years, with an average age of 20.98 years. The sample consists of Levels 200 and 300 students offering undergraduate education programmes. These students were purposively selected because they have had at least one year of tuition in education on campus and are better placed to answer the questions. Two hundred and seventy students were selected for the study out of a population of 450 students. The sampling technique was derived from Yamane (1973), which is used to find an appropriate sample size for issues regarding research in the educational and psychological dimension.

\subsection{Instrumentation}

A Self-Report Survey Questionnaire with closed-ended and open-ended questions was designed and administered to 2 nd and 3rd year teacher education students to ascertain the stressors they encounter and the adaptation stratagems they might employ to manage stress. The Dental Environmental Stress (DES) was adapted to develop an 18-item questionnaire, categorised into academic-related, psychological and health-related items (Cohen, Kamarch, \& Mermelstein, 1983). Some items were sourced from DES whereas others were developed by the researchers and included in the adapted instrument after pilot testing. The reliability coefficient of the questionnaire on DES measured was 0.86, suggesting that the internal consistency was significant. Similarly, a 12-item questionnaire on the Brief Coping Orientation to Problems Experienced (Brief COPE) inventory with a reliability of the questionnaire items at 0.82 , (Folkman \& Lazarus, 1984) was also adapted to calculate the adapting stratagems learners might utilise to lessen the strain that they might encounter. A five-point Likert scale designated as "strongly agree (5)", "Agree (4)", "undecided (3)", "disagree (2)", and "strongly disagree (1)" were used in both situations by respondents to answer the questionnaire items. 


\subsection{Data Collection Procedure}

Data for the study were collected in April 2019 in the department of teacher education of the school of education and leadership, University of Ghana site through permission obtained from the Head of Department. The researchers made personal contacts in the first place with the respondents who are their students to seek their consent by giving them consent form to fill, to give advance information to those who consented to participate in the study and to make the necessary arrangements for the administration of the instruments. The second was the administration of the instrument and collection of the data to coincide with specific lectures to ensure that all the students who were present participated. Levels 200 and 300 students pursuing undergraduate secondary education programmes were used for the study. After distributing the questionnaire to the students, the researchers and their teaching assistants (TAs) waited and collected the answered questionnaire.

\subsection{Data Analysis Procedure}

Stressors experienced by learners of the department of teacher education and the coping stratagems they might adopt to control stress were examined using means and standard deviations. The independent samples t-test was used to find out whether male learners differed from female learners on the stressors they experience as well as coping strategies they might adopt to manage stress.

\section{Results and Discussion}

\subsection{Results}

\subsubsection{Demographic Data}

The open-ended question used in this research was the age of respondents, which learners were asked to supply. Using descriptive statistics, the number of males who participated in the study is $126(46.7 \%)$ and that of females is $144(53.3 \%)$. The mean age of learners presented for this study is 20.98 years.

\subsubsection{Stressors Encountered by Teacher Education Students by Gender}

Research question one sought to find out the stressors encountered by teacher education learners by gender. The outcome of the responses provided by the participants is presented in Table 1.

Table 1. Mean ratings of stressors among teacher education students by gender

\begin{tabular}{llllll}
\hline Category & Stressor & Mean (SD) & & Sig. \\
& & Overall & Male & Female & level \\
\hline Academic Related & Working to meet academic requirements & $4.36(0.88)$ & $4.44(0.73)$ & $4.22(0.99)$ & .122 \\
& Many courses per semester & $3.54(1.24)$ & $3.40(1.29)$ & $3.67(1.19)$ & .084 \\
& Inadequate supply of power and water in halls & $3.89(1.20)$ & $3.77(1.21)$ & $4.00(1.17)$ & .144 \\
& Congested lecture theatres & $3.69(1.30)$ & $3.81(1.23)$ & $3.59(1.36)$ & .168 \\
& Inadequate course materials for assessments & $3.31(1.31)$ & $3.43(1.22)$ & $3.22(1.38)$ & .181 \\
& Facing financial pressure & $3.58(1.29)$ & $3.63(1.44)$ & $3.54(1.16)$ & .590 \\
& Borrowing courses from other Departments & $3.14(1.45)$ & $3.22(1.43)$ & $3.08(1.46)$ & .410 \\
& Apathy received from other Departments where & $2.70(1.38)$ & $2.40(1.21)$ & $2.97(1.46)$ & .001 \\
& Courses are borrowed. & & & \\
& Conflict in time management & $3.51(1.21)$ & $3.44(1.26)$ & $3.58(1.17)$ & .373 \\
& Emotional instability & $3.13(1.26)$ & $2.94(1.34)$ & $3.29(1.17)$ & .021 \\
& Dealing with roommates & $3.40(1.31)$ & $3.33(1.17)$ & $3.46(1.42)$ & .435 \\
& Relationship problems & $3.04(1.27)$ & $2.90(1.23)$ & $3.17(1.31)$ & .082 \\
& Rejection from friends and colleagues & $2.77(1.29)$ & $2.76(1.24)$ & $2.78(1.34)$ & .885 \\
& Loneliness & $2.87(1.38)$ & $2.82(1.31)$ & $2.91(1.45)$ & .585 \\
& Religious activities & $3.31(1.19)$ & $3.24(1.18)$ & $3.38(1.19)$ & .332 \\
& Lack of time for relaxation & $3.24(1.37)$ & $3.09(1.32)$ & $3.38(1.14)$ & .079 \\
& Changes in eating and sleeping habits & $3.73(1.19)$ & $3.54(1.18)$ & $3.90(1.17)$ & .012 \\
& Illness/health problems & $2.89(1.55)$ & $2.75(1.26)$ & $3.01(1.42)$ & .115 \\
& Overall Stressors & $60.1(23.1)$ & $58.9(22.3)$ & $61.2(23.0)$ & .257 \\
\hline
\end{tabular}

Among the academic-related stressors as seen in Table 1, 'working to meet academic requirements' had the maximum mean $(\mathrm{M}=4.36, \mathrm{SD}=0.88)$ with males having the greatest mean $(\mathrm{M}=4.44, \mathrm{SD}=0.73)$ and females having the lowermost $(\mathrm{M}=4.22, \mathrm{SD}=0.99)$ indicating that academic work puts so much stress on the learners particularly males. 
Similarly, from Table 1, the major psychosocial stressor identified was "conflict in time management" $(\mathrm{M}=3.51$, $\mathrm{SD}=1.21)$, with females $(\mathrm{M}=3.58, \mathrm{SD}=1.17)$ having higher conflict in time management compared with their male $(\mathrm{M}=3.44, \mathrm{SD}=1.26)$ counterparts. Despite the difference in means related to the conflict in time management between males and females, the difference was insignificant. Concerning health-related problems, "changes in eating and sleeping habits" $(\mathrm{M}=3.73, \mathrm{SD}=1.19)$, was identified as a high stressor. There was a significant difference in "changes in eating and sleeping habits", such that females $(\mathrm{M}=3.90, \mathrm{SD}=1.17)$ have higher means regarding "changes in eating and sleeping habits" compared with their male $(\mathrm{M}=3.54, \mathrm{SD}=1.18)$ counterparts.

\subsubsection{Coping Strategies Employed by Male and Female Teacher Education Students}

Research two three sought to find out the various coping strategies teacher education students employ by gender when stressed. Table 2 presents the outcome of the responses based on gender as provided by the respondents.

Table 2. Mean ratings of coping strategies employed by teacher education students by gender

\begin{tabular}{|c|c|c|c|c|c|}
\hline \multirow[t]{2}{*}{ Category } & \multirow[t]{2}{*}{ Stressor } & \multicolumn{3}{|l|}{ Mean (SD) } & \multirow{2}{*}{$\begin{array}{l}\text { Sig. } \\
\text { level }\end{array}$} \\
\hline & & Overall & Male & Female & \\
\hline Active coping & $\begin{array}{l}\text { Doing something about the situation, making a move } \\
\text { to discredit stressor }\end{array}$ & $3.82(1.22)$ & $3.93(1.17)$ & $3.73(1.25)$ & .179 \\
\hline Positive reframing & $\begin{array}{l}\text { Observing something great in what is happening, } \\
\text { learning from experience }\end{array}$ & $3.87(1.20)$ & $3.90(1.22)$ & $3.85(1.15)$ & 690 \\
\hline Substance abuse & Using tobacco/alcohol/drug to feel better & $1.78(1.23)$ & $1.85(1.33)$ & $1.70(1.10)$ & .300 \\
\hline Humour & Making fun of the situation & $2.54(1.26)$ & $2.60(1.11)$ & $2.49(1.37)$ & .474 \\
\hline Given up coping & $\begin{array}{l}\text { Giving up the attempt to do anything about the } \\
\text { situation }\end{array}$ & $2.69(1.27)$ & $2.71(1.22)$ & $2.68(1.32)$ & .868 \\
\hline Emotional support & $\begin{array}{l}\text { Getting emotional support/ advice from family and } \\
\text { friends }\end{array}$ & $3.46(1.29)$ & $3.42(1.20)$ & $3.49(1.37)$ & 679 \\
\hline Instrumental support & Getting help and exhortation from lecturers or TAs & $3.39(1.29)$ & $3.33(1.24)$ & $3.45(1.33)$ & .424 \\
\hline Self-distraction & $\begin{array}{l}\text { Doing something to take my mind off the } \\
\text { circumstance, for example, watching TV, going to } \\
\text { movies, shopping, and listening to music }\end{array}$ & $4.11(0.99)$ & $3.98(1.04)$ & $4.22(.93)$ & .040 \\
\hline Religion & Praying and meditating & $3.87(0.94)$ & $3.80(.93)$ & $3.92(.95)$ & .288 \\
\hline Venting & $\begin{array}{l}\text { Expressing negative feelings: indicating outrage at } \\
\text { things/people }\end{array}$ & $3.24(3.44)$ & $3.01(1.28)$ & $3.44(4.56)$ & .299 \\
\hline Acceptance & $\begin{array}{l}\text { Accepting the circumstance as it is, learning to live } \\
\text { with it }\end{array}$ & $3.31(1.21)$ & $3.38(1.09)$ & $3.25(1.31)$ & .377 \\
\hline Denial & $\begin{array}{l}\text { Refusing to believe it happened, not accepting the } \\
\text { situation }\end{array}$ & $3.12(1.26)$ & $3.01(1.26)$ & $3.22(1.26)$ & .178 \\
\hline Total & & $39.2(16.6)$ & $38.8(13.9)$ & $39.4(17.9)$ & .400 \\
\hline
\end{tabular}

Managing stress is very necessary for preventing any undesirable consequence of protracted anxiety. As such learners utilise numerous adapting stratagems in handling stressful circumstances. Most of the learners, as shown in Table 2 were using positive coping strategies such as self-distraction, that is "doing something to take my mind off the situation such as watching TV, movies, shopping, listening to music" $(\mathrm{M}=4.11, \mathrm{SD}=0.99)$, with females having the greatest mean $(\mathrm{M}=4.2, \mathrm{SD}=0.94)$ and males having the least $(\mathrm{M}=3.98, \mathrm{SD}=1.04)$. The rest are active coping like "doing something about the situation/taking action to negate stressor" $(\mathrm{M}=3.82, \mathrm{SD}=1.22)$, with males, $(\mathrm{M}=3.93, \mathrm{SD}=1.17)$ being more active than their female counterparts $(\mathrm{M}=3.73, \mathrm{SD}=1.25)$. On positive refraining such as "seeing something good in what is happening, learning from experience" $(\mathrm{M}=3.87$, $\mathrm{SD}=1.20)$, males were more positive with a mean $(\mathrm{M}=3.90, \mathrm{SD}=1.22)$ than females $(\mathrm{M}=3.85, \mathrm{SD}=1.15)$, although the mean difference between them was insignificant. Additionally, on religion like "Praying/meditating" $(\mathrm{M}=3.87, \mathrm{SD}=0.94)$, females with mean $(\mathrm{M}=3.92, \mathrm{SD}=0.95)$ prayed and meditated more than their male counterparts $(\mathrm{M}=3.80, \mathrm{SD}=0.93)$. This study showed that teacher education students do not indulge in drugs $(\mathrm{M}=1.78, \mathrm{SD}=1.23)$ and that females are more averse to using drugs to feel better $(\mathrm{M}=1.70, \mathrm{SD}=1.10)$ than their male counterparts $(\mathrm{M}=1.85, \mathrm{SD}=1.33)$.

\subsubsection{Gender Differences in Stressors Teacher Education Students Encounter}

Research question three sought to find the gender differences in stressors experienced by teacher education students. The outcome of the responses based on gender as provided by the participants is presented in Table 1 . 
An independent-samples t-test was conducted to compare stressors encountered by male and female teacher education learners. Although there was no significant difference in the overall stressors on males $(M=58.9$, $\mathrm{SD}=22.3)$ and females $(\mathrm{M}=61.2, \mathrm{SD}=23.0)$, there was a significant difference in the scores for males and females on some specific stressors. For instance, there was a significant difference in the scores for males $(\mathrm{M}=2.40$, $\mathrm{SD}=1.21)$ and females $(\mathrm{M}=2.97, \mathrm{SD}=1.46)$ on the causes of stress concerning 'apathy received from other departments where courses are borrowed' as an academic-related issue; $t$ (268) $=-3.503, p=0.001$. Surprisingly, females were undecided on the issue of apathy, as males completely disagreed with that assertion. Similarly, there was a significant difference in the scores for males $(\mathrm{M}=2.94, \mathrm{SD}=1.34)$ and females $(\mathrm{M}=3.29, \mathrm{SD}=1.17)$ on the causes of stress concerning 'emotional instability' as a psychosocial issue; $t(268)=-2.322, \mathrm{p}=0.021$. Finally, there was a significant difference in the scores for males $(\mathrm{M}=3.54, \mathrm{SD}=1.18)$ and females $(\mathrm{M}=3.90, \mathrm{SD}=1.17)$ on the causes of stress for 'changes in eating and sleeping habits' as a health-related issue; $\mathrm{t}(268)=-2.533, \mathrm{p}=0.012$.

\subsubsection{Differences Among Students on the Type of Coping Strategies They Employ by Gender}

Research question four sought to find the gender differences in the adaptation techniques learners might employ to manage stress. An independent-samples t-test was conducted to compare coping strategies adopted by male and female teacher education students. Although, overall, there was no significant difference in the coping strategies adopted by males $(\mathrm{M}=38.8, \mathrm{SD}=13.9)$ and females $(\mathrm{M}=39.4, \mathrm{SD}=17.9)$, specifically there was a significant difference in the scores for males $(\mathrm{M}=3.98, \mathrm{SD}=1.04)$ and females $(\mathrm{M}=4.22, \mathrm{SD}=0.93)$ on the coping strategies they might employ concerning "self-distraction, such as doing something to take my mind off the situation like watching TV, movies, shopping, listening to music"; $\mathrm{t}(267)=-2.06, \mathrm{p}=0.040$.

\subsection{Discussion}

Academic-related stressors were interrogated and the findings suggest that scholastic work such as the writing of assignments, attending lectures, making presentations, writing tests and end of semester examinations put so much pressure on learners. This result aligns with findings of other researches that mentioned scholastic workload, and difficulty in reading textbooks as some of the stressors encountered by learners (Al-Sowygh, 2013; Chao, 2011; Kwaah \& Essilfie, 2017; Saklofske, Austin, Mastoras, Beaton, \& Osborne, 2012). Despite the difference in means related to the conflict in time management between males and females, the difference was not significant. Similarly, it is not surprising that 'conflict in time management', had the greatest mean and standard deviation, which suggests variability in the responses on the psychosocial stressors' scale. These findings agree with the results of some previous studies (Kumiyeboah, 2010; Panchabakesan, 2011; Torto, 2009). Although previous studies (Kumiyeboah, 2010; Torto, 2009) also found 'lack of time for relaxation', and 'inability to concentrate during lecture' as some stressors, this study reported otherwise.

Although the mean difference in gender is insignificant, females had higher overall mean than their male counterparts. This result in gender differences regarding stressors suggests that females are more prone to emotional instability compared to their male counterparts. This is not surprising as research (Calvarese, 2015) has indicated that more females encountered greater degrees of sorrow, disappointment, and nervousness when reacting to stress than their male counterparts.

Additionally, on religion females prayed and meditated more than their male counterparts by their responses. This is predictable as religion plays an important role, particularly among Ghanaian women when it comes to solving problems that confront them specifically with problems that do not have social structures to alleviate its undesirable consequences. This result conforms with the findings obtained by Amponsah and Owolabi (2011), as well as Kwaah and Essilfie (2017) on the stressors experienced by regular and distance education students at the University of Cape Coast. Ghanaians, in general, are highly religious and a bit superstitious and might give spiritual connotation to issues that tend to confront them if they seem not to have any solution at hand.

Furthermore, contrary to the popular notion that students use substance abuse such as 'using tobacco/alcohol/drug to feel better', this study revealed otherwise. These outcomes corroborate research findings of a study conducted by Sideridis (2008), which suggested that there are five significant strain adapting stratagems namely, browsing the internet, sleeping and resting, watching TV or movies and instant messaging as frequently used coping strategies by students.

This study showed that teacher education students do not indulge in drugs and that females are more averse to using drugs to feel better than their male counterparts. This finding is inconsistent with studies such as Misigo (2015) who indicated that male learners reported negative coping strategies such as taking alcohol and drug use.

These results suggest that gender does influence self-distraction as a coping strategy. Specifically, our results suggest that females use self-distraction such as "doing something to take my mind off the situation such as 
watching TV, movies, shopping, listening to music". In other words, females use more adaptive strategies to cope with stress compared with their male counterparts who might use maladaptive strategies.

\subsection{Conclusion}

This investigation has shown that generally, the difference in stressors among male and female teacher education students is insignificant though female students had a high level of stressors compared to their male counterparts. Additionally, the research also revealed that female learners are more likely to be stressed more on specific stressors such as the number of courses offered per semester, inadequate supply of power and water in the halls, conflict in time management, dealing with roommates, lack of time for relaxation and changes in eating and sleeping habits. On the contrary, male students were seen to be more likely to be stressed on working to meet academic requirements, congested lecture theatres, and facing financial pressure.

Correspondingly, the difference in coping strategies adopted by male and female teacher education students is also insignificant but specifically, female students were more inclined to using self-distraction activities to deal with stressful circumstances compared to their male counterparts. The findings also indicated that female learners use adaptive coping stratagems whereas their male counterparts use maladaptive coping stratagems. Besides, it came to light that teacher education students do not necessarily use tobacco/alcohol/drugs as a strategy to cope with stress, though females were more assertive to not using drugs compared to their male counterparts.

\section{Acknowledgment}

This research was not supported by anybody or any institution. As a new department the researchers wanted to evaluate the differences in gender on stressors encountered by their students and the coping strategies, they might adopt to control stress. We wish however to thank all the students who took part in the study.

\section{References}

Aldwin, C. M. (2007). Stress, Coping, and Development: An Integrative Approach (2nd ed., p. 432). New York, NY: Guilford.

Al-Sowygh, Z. H. (2013). Academic distress, perceived stress and coping strategies among dental students in Saudi Arabia. The Saudi Dental Journal, 25(3), 97-105. https://doi.org/10.1016/j.sdentj.2013.05.002

Amponsah, M., \& Owolabi, H. O. (2011). Perceived stress levels of fresh university students in Ghana: A case study. British Journal of Educational Research, 1(2), 153-169.

Anbumalar, C., Dorathy, A. P., Jaswanti, V. P., Priya, D., \& Reniangelin, D. (2017). Gender differences in perceived stress levels and coping strategies among college students. The International Journal of Indian Psychology, 4(4), 2349-3429.

Brougham, R. R., Zail, C. M., Mendoza, C. M., \& Miller, J. R. (2009). Stress, sex differences, and coping strategies among college students. Current Psychology, 28(2), 85-97. https://doi.org/10.1007/s12144-009-9047-0

Calvarese, M. (2015). The effect of gender on stress factors: An exploratory study among university students. Social Sciences, 4, 1177-1184. https://doi.org/10.3390/socsci4041177

Chao, R. C. (2012). Research managing perceived stress among college students: The roles of social support and dysfunctional coping. Journal of College Counseling, 15, 5-22. https://doi.org/10.1002/j.2161-1882.2012.00002.x

Chen, H., Wong, Y., Ran, M., \& Gilson, C. (2009). Stress among Shanghai University students. Journal of Social Work, 9(3), 323-344. https://doi.org/10.1177/1468017309334845

Cohen, S., Kamarch, T., \& Mermelstein, R. (1983). A global measure of perceived stress. Journal of Health and Social Behavior, 24, 385-396. https://doi.org/10.2307/2136404

Conner, J., Pope, D., \& Galloway, M. (2009/2010). Success with less stress. Educational Leadership, 67(4), 54-57.

Craighead, W. E., \& Miklowitz, D. J. (1957). Psychopathology: history, diagnosis, and empirical foundations. Craighead, Linda W. Hoboken, N. J.: John Wiley \& Sons. 2008. ISBN 9780471768616. OCLC 181903762.

Desmarais, S., \& Alkisnis, C. (2005). Gender issues. In J. Barling, E. K. Kelloway \& M. R. Frone (Eds.), Handbook of work stress (pp. 487-515). California: Sage.

Donaldson, D., Prinstein, M. J., Danovsky, M., \& Spirito, A. (2000). A pattern of children's coping with life 
stress: Implications for clinicians. American Journal of Orthopsychiatry, 70(3), 351-359. https://doi.org/10.1037/h0087689

Dyson, R., \& Renk, K. (2006). Freshmen adaptation to university life: Depressive symptoms, stress, and coping. Journal of Clinical Psychology, 62(10), 1231-1244. https://doi.org/10.1002/jclp.20295

Gomes, A. R., Faria, S., \& Lopes, H. (2016). Stress and psychological health. Western Journal of Nursing Research, 38(11), 1448-1468. https://doi.org/10.1177/0193945916654666

Gyambrah, M., Sesay, R. M., \& Amponsah, M. O. (2017). Stress levels and management strategies among distance education students. International Review of Social Sciences and Humanities, 12(2), 33-51.

Kania, S. K. (2014). The relationship between gender differences and stress. The Huron University College Journal of Learning and Motivation, 52(1), 91-101.

Kumi-Yeboah, A. (2010). A Look at the trend of distance and adult education in Ghana. International Forum of Teaching and Studies, 6(1), 19-28.

Kwaah, C. Y., \& Essilfie, G. (2017). Stress and coping strategies among Distance Education Students at the University of Cape Coast, Ghana. Turkish Online Journal of Distance Education-TOJDE, 18(3), 120-134. https://doi.org/10.17718/tojde.328942

Lazarus, R. S. (1984). Stress, appraisal, and coping. Folkman, Susan. New York: Springer Pub. Co. ISBN 0826141900 . OCLC 10754235.

Lazarus, R. S, \& Folkman, S, (1984). Stress, appraisal, and coping. New York: Springer.

Lin, S., \& Huang, H. (2014). Life stress and academic burnout. Active Learning in Higher Education, 15(1), 7790. https://doi.org/10.1177/1469787413514651

Misigo, B. L. (2015). Gender difference in the perceived level of stress and coping strategies among university students in Kenya: A case of public universities. International Academic Journal of Social Sciences and Education, 1(4), 44-52.

Panchabakesan, S. (2011). Problems and prospective in distance education in India in the 21 st century. Problems of Education in the 21st Century, 30,113-122.

Robotham, D., \& Julian, C. (2006). Stress and Higher education student: A critical review of the literature. Journal of Further and Higher Education, 30, 107-117.

Roseman, I. J. (1996). Appraisal determinants of emotions: Constructing a more accurate and comprehensive theory. Cognition \& Emotion, 10(3), 241-278. https://doi.org/10.1080/026999396380240

Saklofske, D. H., Austin, E. J., Mastoras, S. M., Beaton, L., \& Osborne, S. E. (2012). Relationships of personality, affect, emotional intelligence and coping with student stress and academic success: Different patterns of association for stress and success. Learning and Individual Differences, 22(2), 251-257. https://doi.org/10.1016/j.lindif.2011.02.010

Scherer, K. R. (2009). The dynamic architecture of emotion: Evidence for the component process model. Cognition \& Emotion, 23(7), 1307-1351. https://doi.org/10.1080/02699930902928969

Sideridis, G. D. (2008). The regulation of effect, anxiety, and stressful arousal from adopting mastery-avoidance goal orientations. Stress and Health, 24(1), 55-69. https://doi.org/10.1002/smi.1160

Sitz, E. H., \& Poche, N. (2006). Gender Differences in Relationship between Optimism and Perceived Stress. National Undergraduate Research Clearinghouse. Retrieved from http://www.webclearinghousenet/volume/

Tajularipin, S., Aminuddin, H., Vizata, S., \& Saifuddin, A. (2009). The level of stress among students in Urban and rural secondary schools in Malaysia. European Journal of Social Sciences, 10(2), 43-65.

Thawabieh, A. M., \& Qaisy, L. M. (2012). Assessing Stress among University Students. American International Journal of Contemporary Research, 2, 110-116.

Thoits, P. A. (1995). Identity-relevant events and psychological symptoms: A cautionary tale. Journal of Health and Social Behavior, 36, 72-82. https://doi.org/10.2307/2137288

Tomaschewski-Barlem, J. G., Lunardi, V. L., Ramos, A. M., Da Silveira, R. S., Devos-Barlem, E. L., \& Ernandes, C. M. (2014). Characteristic signs and symptoms of the burnout syndrome experienced by undergraduate nursing students. Journal of Nursing and Socio-Environmental Health, 1(1), 79-86. https://doi.org/10.15696/2358-9884/jonse.v1n1p79-86 
Torto, B. A. (2009). Problems of part-time students in Ghana: Implications for distance education. African Journals Online, 7. https://doi.org/10.4314/mc.v7i1.61536

\section{Copyrights}

Copyright for this article is retained by the author, with first publication rights granted to the journal.

This is an open-access article distributed under the terms and conditions of the Creative Commons Attribution license (http://creativecommons.org/licenses/by/4.0/). 